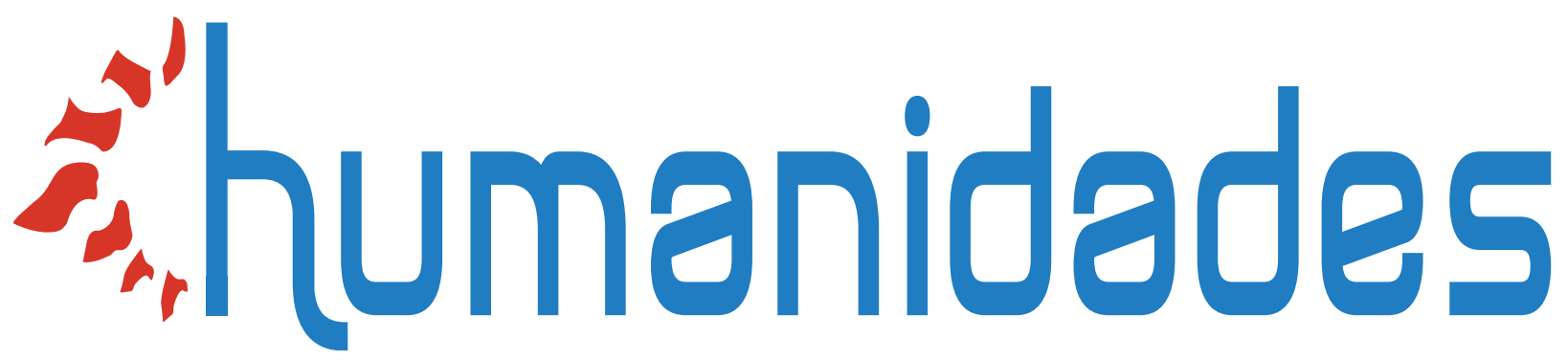

\title{
Gottfried Benn y la sublime belleza de la crueldad
}

\author{
Javier Martín Párraga
}

DOI: https://doi.org/ I0.155 I7/h.vI0il .39658

https://revistas.ucr.ac.cr/index.php/humanidades/index

(c) $(7)\left(\Theta_{\mathrm{EY}}\right.$

Universidad de Costa Rica 


\section{thumanidades}

Revista Humanidades

ISSN: 2215-3934

humanidades@ucr.ac.cr

Universidad de Costa Rica

Costa Rica

\section{Gottfried Benn y la sublime belleza de la crueldad}

Martín Párraga, Dr. Javier

Gottfried Benn y la sublime belleza de la crueldad

Revista Humanidades, vol. 10, núm. 1, 2020

Universidad de Costa Rica, Costa Rica

Disponible en: http://www.redalyc.org/articulo. oa?id=498060395009

DOI: https://doi.org/10.15517/h.v10i1.39658

Todos los derechos reservados. Universidad de Costa Rica. Esta revista se encuentra licenciada con

Creative Commons. Reconocimiento-NoComercial-SinObraDerivada 3.0 Costa Rica. Correo electrónico:

humanidades@ucr.ac.cr/ Sitio web: http: //revistas.ucr.ac.cr/index.php/humanidades

Esta obra está bajo una Licencia Creative Commons Atribución-NoComercial-SinDerivar 3.0 Internacional. 
Desde el arte, la literatura y la comunicación

\section{Gottfried Benn y la sublime belleza de la crueldad}

Gottfried Benn and the Sublime Beauty of Cruelty

Dr. Javier Martín Párraga

Universidad de Córdoba, España

javier.martin@uco.es

DOI: https://doi.org/10.15517/h.v10i1.39658

Redalyc: http://www.redalyc.org/articulo.oa?

(iD http://orcid.org/0000-0002-9739-0070

$\mathrm{id}=498060395009$

Recepción: 24 Agosto 2019

Aprobación: 24 Octubre 2019

\section{Resumen:}

Morgue und andere Gedichte, opus primum del poeta germano Gottfried Benn, publicado en el año 1912, supuso una revolución en la poesía alemana del momento debido a su naturaleza radical y provocadora. En este artículo se lleva a cabo un estudio pormenorizado del poemario completo, partiendo del marco teórico constituido tanto por pensadores como Addison, Burke o Dessoir que definieron el concepto de sublime como por otros poetas que, como Benn, se adhieren a una concepción sublime del hecho poético que, en muchas ocasiones lleva a despreciar la belleza formal canónica en pos de una cierta escatología que es a la par socialmente provocadora y fecundamente filosófica.

Palabras clave: Literatura moderna, Análisis literario, Crítica literaria, Poesía.

\section{Abstract:}

Gottfried Benn's opus primum, Morgue und andere Gedichte was published in 1912 and it produced a radical change in contemporary German poetry. This paper offers an in-depth analysis of the whole book of poems, employing as a theoretical framework both the theories of those experts which contributed to the establishment of the concept of sublimity such as Addison, Burke or Dessoir as well as other poets who, like Benn himself, embraced a conception of sublimity which quite frequently made them renounce canonical formal beauty; which they replace by a certain eschatology which is both socially shocking and philosophically fertile.

KEYWORDS: Modern Literature, Literary analysis, Literary criticism, Poetry.

\section{Pre-operatorio: algunas reflexiones Sobre el concepto "Sublime"}

Antes de adentrarse en el radical poemario de Gottfried Benn del que trata el presente artículo se considera pertinente realizar un previo y breve recorrido por el concepto de sublime que el autor abraza tanto en esta, su opus primum, como en la totalidad de su corpus literario posterior. En este sentido, no cabe duda de que el Romanticismo rompió con numerosas convenciones poéticas. De hecho, Joseph Hillis Miller, una de las figuras más relevantes dentro del heterogéneo grupo de críticos literarios que conformaron la deconstrucción, la cual conectaba ya en 1972 el movimiento romántico con la nueva y radical aproximación a la crítica textual que él y otros filósofos y críticos defendían como rupturista a la par que necesaria.

Una de las múltiples novedades que el movimiento romántico trajo consigo está relacionada con los conceptos de decoro y sublimación de la belleza, atribuibles a la poesía anterior, lo cual queda ciertamente desdibujado tras las numerosas piezas líricas románticas en las que se nos presenta una belleza terrible, destructora o, incluso, macabra. De este modo, en la lengua inglesa el sustantivo "awe" que implicaba un sentimiento de reverencia mezclada con temor forma el adjetivo "awesome" que conserva sin duda las connotaciones de temor referencial, pero añade un claro tono positivo de admiración. Otros sustantivos experimentan una evolución similar, como "terrific", "brutal” o (más recientemente) "wicked”, gracias a lo que Culpeper (1997) denomina como "melioración de significado”. Este proceso, mediante el cual términos 
que originalmente implicaban significados poderosos pero negativos pasan a denotar situaciones positivas, aunque intensas, comienza precisamente durante el Romanticismo.

Quizá el ejemplo más célebre de hasta qué punto el Romanticismo acepta como poéticos elementos anteriormente tachados de siniestros, mórbidos o incluso escatológicos lo constituya el poemario del poeta francés Charles Baudelaire; exponente de un Romanticismo tardío que, en muchos sentidos, habría de ser el más influyente en la literatura posterior. Siguiendo con lo anterior, la influencia de Baudelaire tanto para el modernismo y postmodernismo como para la cultura pop (el movimiento sociocultural conocido como gótico sería impensable sin este poeta, así como sin el norteamericano Edgar Allan Poe) ha sido de sobra analizada en diversos estudios. Se estima pertinente, sin embargo, señalar que el seminal (y en gran medida también revolucionario) filósofo y crítico literario, Walter Benjamin, sitúa a Baudelaire al comienzo mismo de la modernidad que de manera tan brillante contribuyera a definir en muchos de sus escritos. La importancia que da Benjamin a este poeta como precursor de la modernidad literaria queda plasmada en dos de sus obras: Charles Baudelaire: a Lyric Poet in the Era of High Capitalism y The Writer of Modern Life: Essays on Charles Baudelaire.

En el año 1857, el poeta galo da a la imprenta el genial y controvertido poemario Les fleurs du mal. En este, Baudelaire explora los rincones más sórdidos del alma humana, al mismo tiempo que sirve de Cicerón para que el lector conozca de primera mano los callejones más sucios y oscuros del París decimonónico. Como Beryl Schlossman (1993) apunta: "Baudelaire's equation of 'vive la revolution!' with 'vive la mort!' is echoed in his declared desire to be both victim and executioner" (p. 68) ${ }^{1}$. De hecho, en Les fleurs du mal, el autor da inicio al poemario dirigiéndose "Au lecteur" (al que poco después definirá como "Hypocrite lecteur, mon semblable- mon frère!" ${ }^{2}$, y afirmando lo siguiente:

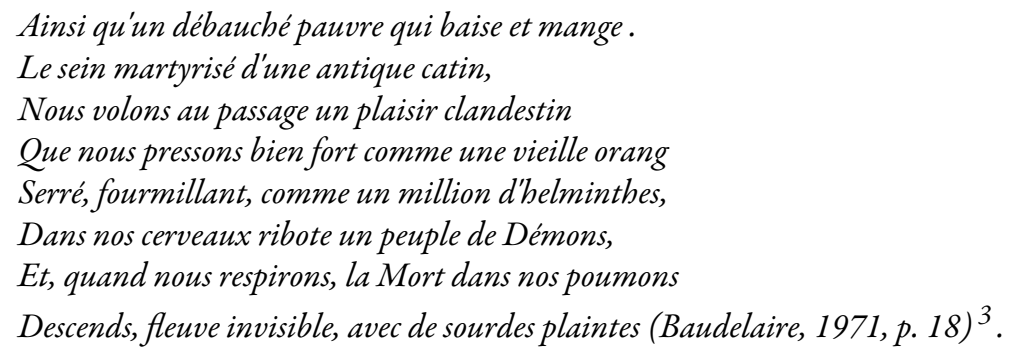

Como podemos apreciar en esta breve cita del poemario de Baudelaire (que no solo escandalizó a la sociedad y élite cultural del momento, sino que le valió serias complicaciones legales), para el año 1912 ya habían sido publicados textos poéticos que desafiaban el entendimiento tradicional (canónico, nos atreveríamos a decir) de la poesía en la que esta aspiraba a la sublimación estética y espiritual. De hecho, como Kai Hammermeister (2002) nos recuerda, el filósofo Arthur Schopenhauer comenzó ya a finales del siglo XIX a demoler los cimientos que sustentaban la visión idealista del arte que había imperado durante los siglos anteriores (pp. 111-127).

Tras Baudelaire, otro genial poeta francés, Paul Verlaine, acuñará en 1884 el término "Poète maudit" en su obra Les poètes maudits (1888). De acuerdo con Thomas Solène (2014), la concepción del poeta maldito impregna la totalidad de su producción literaria, al mismo tiempo que le permitía vincularse con toda una generación de autores que, como él mismo, se enorgullecían de desafiar tanto las convenciones sociales como las estéticas (aún cuando esta actitud llevaba aparejado el pago de un alto precio), como puedan ser Stéphane Mallarmé, Aloysius Bertrand, Arthur Rimbaud, Alice de Chambrier o Comte de Lautréamont. Nos permitimos reproducir aquí el soneto que Verlaine dedicó a Baudelaire en 1892, en el que el concepto de poeta maldito se aprecia a la perfección:

Je ne t'ai pas connu, je ne t'ai pas aimé, 


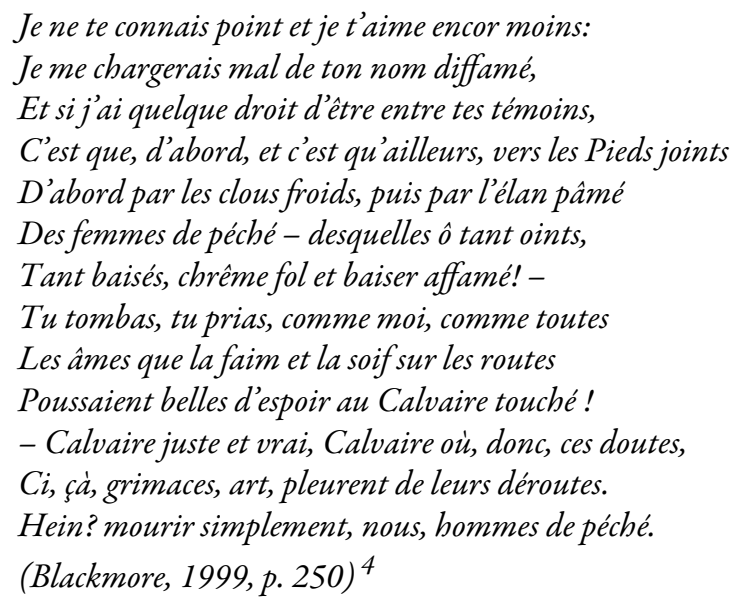

Cabría en este punto adentrarse, si bien de manera necesariamente sucinta, en el concepto de "sublime" en el campo de la Filosofía, que se inicia con el seminal tratado de Longinus Peri Hupsous. El texto de Longinus, perdido durante más de mil años se recupera en el siglo XVI (si bien de manera mutilada) y ejerce una influencia central en filósofos posteriores, que pretenden establecer la verdadera noción de lo sublime, al mismo tiempo que discernir si esta resulta o no necesariamente incompatible con la belleza formal (Eck, 2012). En lengua inglesa, Joseph Addison redacta Pleasures of the Imagination (1712) donde entre otras cuestiones reflexiona sobre la terrible belleza natural (Higuchi 1994 y Martín Párraga 2015). Pero es sin duda Edmund Burke el mejor exponente de lo sublime en el contexto de la filosofía en el contexto de la cultura anglosajona. Para Burke, que publica A Philosophical Enquiry into the Origin of Our Ideas of the Sublime and Beautiful en el año 1757, los conceptos de sublime y belleza estética son mutuamente excluyentes. Asimismo, lo sublime produce una suerte de "dolor negativo" del que deriva un placer estético. El papel de Burke como teórico (e impulsor) del concepto de sublime es de sobra conocido, aunque creemos que merece la pena mencionar a este respecto el artículo de Mark Blackwell (2003), “The sublimity of taste in Edmund Burke's A Philosophical Enquiry into the Origin of Our Ideas of the Sublime and Beautiful".

La obra de Burke despertará la atención de prominentes filósofos alemanes, como Moses Mendelssohn o Inmanuel Kant. Mendelssohn lee con sumo interés a Burke, pero el concepto sobre lo sublime del filósofo inglés se aleja en demasía de la teoría principal que mantenía, basada en lo que denominamos estética de la perfección. Sin embargo, algunas ideas de Burke se abren camino en su Rhapsodie, donde Mendelssohn ya refiere al "terror agradable". La influencia de Burke en Mendelssohn fue magistralmente estudiada por Alexander Altmann (1973) en su trabajo Moses Mendelssohn: A Biographical Study.

Junto con Mendelssohn, también Schopenhauer y Hegel considerarán el papel de lo sublime, así como sus connotaciones psicológicas y éticas. La importancia del concepto de lo sublime en Hegel es estudiada con detenimiento por David James (2012) y por el crítico Kirk Pillow, que analiza esta misma cuestión en el caso de Kant (2000).

Por último, ya en el siglo XX, otro destacado filósofo y psicólogo alemán, Max Dessoir (1906), da a la imprenta Ästhetik und allgemeine Kunstwissenschaft, donde distingue cinco tipologías estéticas: lo hermoso, lo sublime, lo trágico, lo feo y lo cómico. De esta manera, como se puede apreciar, el lector alemán que abriera un volumen de poesía en el año 1912 debía estar ya de sobra familiarizado con el concepto de lo sublime y, al menos parcialmente, acostumbrado a leer obras líricas en las que la belleza era sustituida por una sensación apabullante y poderosa que no aspiraba a resultar estéticamente placentera o moralmente útil. Sin embargo, las letras germanas quedaron conmocionadas cuando ese año Gottfried Benn (1886-1956) publicó un primer poemario que, desde su título, resultaba tan sugerente como provocador y horrendo. Aquí se refiere a Morgue und andere Gedichte, un libro breve cuya primera edición, de tan sólo 500 copias, tardó una semana en agotarse. De este modo, el médico y poeta de 26 años se convirtió casi de manera instantánea en una figura eminente de las letras alemanas, en figura clave del incipiente expresionismo poético alemán, 
al mismo tiempo que en causante, de todo punto involuntario, de una tormenta mediática que no volverá a repetirse en la literatura occidental hasta que en el año 1988 The Satanic Verses le valieran a Salman Rushdie una fatwa y el estatus de ídolo cultural. De este modo, Joseph Frank (2012) no duda en afirmar que "By no means a new or undiscovered writer, Benn published his first book-a volume of brutal, Expressionist poems called Morgue —in 1912 at present, he is considered the greatest German poet since Rilke” (p. 116) ${ }^{5}$.

\section{Disección de Morgue und ANdere Gedichte}

Morgue und andere Gedichte se abre con un poema titulado "Kleine Aster" ("Pequeño aster"). El mismo describe la autopsia de un ciudadano anónimo, el conductor de un camión de cervezas al que, tras sufrir un accidente fatal, se le realiza la autopsia. La voz poética, hierática y desprovista de emociones aparentes explica que alguien había colocado una pequeña flor (la aster que da título al poema) entre los dientes. El significado metafórico de esta pequeña flor, de profundas resonancias en la poesía romántica, se transforma radicalmente en la poesía de Benn; ya que, como Larson Powell (2008) explica, "The blue flower of Romantic nature is here ritually laid to last rest, together with the subject of humanist autonomy revealed as dissected anatomy, all to the ironized tones of an implicitly liturgical ceremoniousness" (p. 98) ${ }^{6}$. En la composición de Benn, pues, el aster pasa a ser una flor funeraria, que resbala de la boca cuando el forense abre el paladar de la víctima con un largo cuchillo, para acabar alojada en el cerebro del cadáver. El galeno introduce el aster en el pecho del cadáver, entre el serrín, para enterrarlo en el cuerpo del pobre conductor y Benn concluye el poema como sigue, "Trinke dich satt in deiner Vase! Ruhe sanft, kleine Aster!". Como en todas las ocasiones posteriores en que citamos a Benn en alemán, ofrecemos a continuación la traducción al castellano de Verónica Jaffé (1991): “¡Bebe hasta la saciedad en tu florero! ¡Descansa en paz, pequeña aster!”.

No resulta sorprendente, a tenor de este inicio, que el poemario causara una controversia espectacular y llegara a ser prohibido en el año 1916. En primer lugar, por mucho que Baudelaire hubiera resultado cáustico en el pasado, que los filósofos referidos en el epígrafe anterior estudiaran el concepto sobre lo sublime y lo distanciaran del concepto de belleza y que Rilke hubiera ya publicado un poema titulado Morgue en 1907, comenzar un poemario con un aséptica escena forense en la que se describe como "Ein ersoffener Bierfahrer wurde auf den Tisch gestemmt" "El cadáver del conductor de un camión de cerveza fue alzado sobre la camilla”) resultaba sin duda provocador y desconcertante. Pero si tan solo se tratara de lo escatológico de la descripción anatómica, probablemente el texto de Benn ni hubiera provocado semejante tumulto entre las letras alemanas del momento ni podría enraizarse con la tradición de lo sublime a la que referimos en el presente artículo. De hecho, como Peter M. McIsaac nos recuerda, el término "morgue" (tomado del francés en detrimento del sustantivo alemán "Leichenschauhaus"), el cual está íntimamente relacionado con la exposición pública de cadáveres que en aquel momento se realizaba en Francia y Alemania, supuestamente con fines educativos y de concienciación frente a las enfermedades venéreas. Así pues, "the curious hold that gawking at corpses on display had on contemporaries prompted German-speaking writers and critics to develop the morgue into a critical topos of exposure and visuality" (McIsaac, 2019, p. 215) ${ }^{7}$.

Sin embargo, la provocación de Benn va mucho más allá de ofrecer en su poesía vívidas descripciones de las mismas imágenes que innumerables ciudadanos alemanes contemplaban con mórbida fascinación en estas exposiciones públicas de cadáveres. Y lo hace en dos sentidos. Al elegir el aster como flor para su mórbido poema, Gottfried Benn nos obliga a plantearnos el sentido mismo de todo símbolo u honra funeraria. La florecilla que alguien ha colocado en la boca del fallecido como símbolo de respeto acaba siendo enterrada en el pecho de este, siendo literalmente alimentada por la sangre del difunto y, lo que resulta más inquietante, robándole el honor de una breve despedida si quiera por parte del cirujano que, en su lugar, reflexiona sobre el destino del aster. De este modo, Benn nos presenta no el funeral de un congénere, sino el de una flor, lo que nos obliga a mirar de frente a lo que otro genio alemán, Sigmund Freud, definiera como unhemlich 
en su artículo "Das Unheimliche" (1919). De este modo, al dirigir nuestra atención hacia la flor, Benn nos invita (conmina, cabría aseverar) a observar hasta qué punto el cadáver se ve desprovisto de toda inmanencia, nobleza o dignidad. Para Benn, una vez perdida la vida, el ser humano no es sino un despojo, un resto orgánico que para el profano resulta nauseabundo y para el ojo acostumbrado del forense no es sino insignificante en extremo. Remitiéndose al seminal ensayo de Freud "Das Unheimliche" (1919), al hacernos contemplar lo que nos resulta totalmente alejado de la domesticidad reconfortante del día a día (un aster que se nutre de un cadáver humano), Benn nos lleva a enfrentarnos con la muerte, que conocemos de manera consciente, pero hemos convertido por mero afán de supervivencia emocional en algo totalmente oculto para nuestro consciente (unheimlich). Así pues, el concepto mismo de existencia tras la muerte resulta descabellado. En segundo lugar, y desde un prisma metaliterario, al enterrar en un cuerpo humano la flor que en la tradición lírica simbolizaba las honras funerarias, Benn está deconstruyendo por completo el género elegíaco. Sin embargo, en la sala de autopsias a la que nos traslada Benn, desprovista de toda belleza, emotividad o dignidad humanas acontece algo que nos eriza el cabello y nos obliga a mirar de frente al doppelganger en que sabemos se convertirá nuestro cuerpo cuando el corazón deje de latir, pero que tan cuidadosamente tratamos de olvidar en nuestra existencia diaria.

También debemos recordar en este momento a Kant, que defendía en los siguientes términos la relación existente entre la naturaleza y lo sublime:

Thus, too, delight in the sublime in nature is only negative (whereas that in the beautiful is positive): that is to say, it is a feeling of imagination by its own act depriving itself of its freedom by receiving a final determination in accordance with a law other than that of its empirical employment. In this way it gains an extension and a might greater than that which it sacrifices. But the ground of this is concealed from it, and in its place it feels the sacrifice or deprivation, as well as its cause, to which it is subjected $(2016, \text { p. } 68)^{8}$.

Tras introducir al lector de forma abrupta en el aséptico y frío ambiente del cuarto de disección en el primer poema, Benn continúa examinando con ojo implacable lo que acontece en el mismo en la siguiente composición, titulada "Shöne Jugend". Una vez más, desde el título parece que Benn quiere manifestar un posicionamiento poético sublime. Y para Benn, como para Burke, lo sublime y lo hermoso van a ser necesariamente autoexcluyentes. El poema comienza de nuevo con un cuerpo sobre la mesa de autopsias, aunque en esta ocasión no se trata de un adulto, sino de "eines Mädchens, das lange im Schilf gelegen hatte" ("una niña que había estado mucho tiempo entre los juncos”). Cabría pensar que el título, que refiere a una hermosa juventud, está directamente conectado con la joven fallecida. De ser así, Benn estaría sin duda tratando una temática de naturaleza escatológica y provocativa. Sin embargo, muy pronto se dará cuenta el lector de que el cuerpo de la pequeña que yace sobre la fría mesa de autopsias con "war die Speiseröhre so löcherig" ("el esófago [que] estaba tan agujereado") no solo no es la protagonista del poema, sino que su papel en el mismo será meramente marginal, circunstancial cabría decir. Si en el poema anterior los restos humanos servían de urna funeraria para una flor, en este nuevo poema "Schließlich in einer Laube unter dem Zwerchfell/ fand man ein Nest von jungen Ratten" ("Por fin, en una pérgola bajo el diafragma hallaron un nido de pequeñas ratas").

Serán precisamente estas ratas, que se han estado alimentando de la sangre y vísceras de la niña, las que disfrutaban de la hermosa juventud que da título al poema. De nuevo, nos vemos obligados a asumir que en la poesía expresionista del Benn de Morgue lo sublime y lo bello son conceptos opuestos, tanto en lo estético como en lo moral. Desde una perspectiva estética, presentar el cuerpo yermo en descomposición de una niña virginal siendo devorado por una camada de ratas no resulta desde luego una imagen visualmente atractiva desde una perspectiva canónica. En el plano moral, la actitud del narrador del poema es incluso más estremecedora por la frialdad con que refiere a la niña muerta (que no causa en él sentimiento alguno), en contraste con la piedad que le produce "ein kleines Schwesterchen lag tot" ("una [rata] hermanita yacía muerta") antes de ser descubiertas y la suerte que corren las supervivientes: "Ach, iwie die kleinen Schnauzen quietschten!” (“iAy, cómo chillaban los pequeños hocicos!”). Y es que, de hecho, la hermosa juventud del 
título refiere no a la joven sino a las ratas: "Die andern lebten von Leber und Niere, tranken das kalte Blut und hatten hier eine scho\#ne Jugend verlebt" ("Las otras se alimentaban del hi\# gado y del rin\#ón, bebi\#an la sangre fri\#a y pasaron aqui\# una hermosa juventud”). Podríamos en este momento considerar la posibilidad de que Benn estuviera en este poema realizando una crítica de las duras condiciones de vida que los alemanes de clase baja del momento se veían obligados a soportar y que, en demasiadas ocasiones, les imponía una forma de vida completamente rodeada por la suciedad, mientras el sector privilegiado de esa misma sociedad no les brindaba sino una deshumanizada indiferencia. Creemos, sin embargo, que esta lectura no responde al planteamiento de Benn. Por una parte, como Ian Egon Morgan (2009) explica:

Benn spent most of his life in highly agitated political times and the developments on that front helped shape and influence his world view; more concretely and importantly, his artistic convictions and practices grew out of a tradition that was almost exclusively shaped by politics. But at the same time, Benn's lyrical work is strangely enough almost completely apolitical. He was certainly not an apolitical man but his poetry, his true art, never became political (pp. 47-48) ${ }^{9}$.

Por otra parte, la lectura del poema (o de este fragmento en concreto) en términos de denuncia o crítica social conectaría a Benn y su poesía con los artistas marxistas a los que despreció toda su vida. El desprecio del autor a estos intelectuales resulta patente al estudiar tanto su poesía y prosa como la correspondencia que mantiene con el poeta alemán exiliado en Francia Klaus Mann (2013, pp. 207-08) y en la que explotan definitivamente las tensiones entre ambos, que venían conformándose desde años atrás a raíz de la visión de Mann como transmisor de valores sociales. En palabras de Alison Ford (1993): "[Mann] proposed, in his debate with Gottfried Benn, that should the writer fail to address the specific historical moment by challenging its political and social context, then he would bring about his own downfall with his work judged as irrelevant" (p. 339) ${ }^{10}$.

Estamos, por lo tanto, convencidos de que la frialdad con la que reacciona el poeta a la niña muerta en contraste con la piedad que le suscitan las crías de rata no está relacionada con posicionamientos políticos sino con la búsqueda de la sublimidad y de una revolución poética. Resulta en este momento importante citar a Richard Murphy (1999):

They [Döblin, Benn and Kafka] are "avant-garde" not only in their interrogation of the way that these conventions support the idea of the "normalcy" of the bourgeois world, but in their creation of a set of "oppositional discourses" intended to overhaul the institutionalized artistic means through which certain values are privileged (p. 41) ${ }^{11}$.

También Friedrich Kittler (1990) observa en Benn lo que él denomina un "epochal displacement":

Verbal transmission as neurosis, without any basis in a transcendental or creative Poet's ego; medial selection without reference to the real, to the incomprehensible background of all media. The word that had always reached people operates at a certain psychic reaction threshold, which was called the discourse of nature and the nature of discourse. [Ro\#nne's] Psychophysics does away with both of them (p. 243) ${ }^{12}$.

El tercer poema de Morgue, "Kreislauf" versa sobre una prostituta fallecida a la que el sepulturero arranca una muela de oro que aún permanecía anclada a su boca. Como podemos observar, la circulación o ciclo que da título a la composición no es la sanguínea (o el paso natural de la vida a la muerte) sino la económica. La sangre de una mujer que se ganó la vida comerciando con su cuerpo hace tiempo dejó de fluir, lo que no impide en modo alguno que una parte que estuvo unida a su propio cuerpo siga siendo un objeto mercantil en movimiento. El mensaje subyacente en este "Kreislauf" es, por lo tanto, terrible ya que el cuerpo humano desprovisto de vida vuelve a ser mostrado como un mero objeto. Si en textos anteriores los cadáveres habrían de servir de floreros siniestros o de alimento para alimañas (lo cual no deja de constituir parte del ciclo vital en el que la muerte engendra o permite la vida), en este caso el esqueleto de la prostituta no servirá sino para comprar bienes o servicios materiales. No resultaría descabellado aquí llevar a cabo una interpretación del poema desde un prisma lacaniano o, incluso, desarrollar un análisis del mismo a partir de los planteamientos del filósofo Slavoj Žižek (1994). Consideramos, no obstante, que por excitante (o fructífera) que esta lectura 
pudiera resultar, nos apartaría por completo del posicionamiento moral y estético de Benn. El colofón al poema, en la más pura tradición de Nietzsche y Schopenhauer, resulta nihilista al tiempo que parodia los textos sagrados y la interpretación interesada y material que de los mismos se ha hecho a lo largo de la historia, puesto que la justificación del sepulturero para expoliar el cadáver no es sino que, "Denn, sagte er, nur Erde solle zur Erde werden" ("sólo la tierra debe volver a la tierra").

Tras este poema, el lector encontrará el más famoso y reproducido de los textos de Morgue, "Negerbraut". Si hasta ahora la mirada fría, aséptica pero estremecedora del poeta cirujano se había detenido en cuerpos solitarios en los que no se atinaba si quiera un indicio de sensualidad, con "Negerbraut" se introducen por primera vez elementos de este tipo. Ahora no es ya uno el cuerpo sobre la mesa de autopsias, sino que en esta ocasión nos encontramos con una inesperada pareja. Se trata de una virginal joven rubia a la que el inmisericordioso destino ha llevado a compartir lecho con un pobre de raza negra. Los ecos del topos medieval de la danza macabra, que comienza en el siglo XII con los Vers de la Mort y en los que "se relata a través de 50 estrofas, el viaje que hizo la Muerte hacia Roma, como si fuera una peregrina, llevándose en su trayecto, a cardenales, obispos, reyes, mendigos, nin\# os y gentes de toda condición” (González, 2014, p. 30). En otras palabras, este arquetipo literario nos presenta a una muerte democrática que se encarga de destruir de manera postrera todas y cada una de las barreras sociales, para llevar al mismo punto a reyes y mendigos.

Queremos hacer hincapié en este punto, ya que Benn cometería años después el error terrible de simpatizar de manera breve con el nazismo, aunque no tardara en reconducir su postura; como él mismo reconoce en su obra autobiográfica Doppelleben (1950). De hecho, el infausto Tercer Reich no tarda en perseguir y castigar a Benn, como prueba la siguiente cita aparecida en 1936 en Gesammelte Werk, revista de las SS: “Aber Herr Benn wühlt seinen Stift nicht nur in stinkenden Wunden, er macht auch in Erotik, und wie er das macht, das befähigt ihn glatt zum Nachfolger jener, die man wegen ihrer widernaturlichen Schweinereien aus dem Hause jagte" (Hillebrand, 1987, p. 138) ${ }^{13}$.

Sin embargo, abundan aún hoy las voces que siguen insistiendo en el supuesto filonazismo de Benn (paradójicamente, una de las voces que mayor desprecio mostró hacia Gottfried Benn en este sentido fue precisamente la de un Günter Grass cuyas memorias habrían de reconocer un pasado nazi bastante más consciente y comprometido que el del propio objeto de sus mordaces ataques). No obstante, hoy en día la mayor parte de críticos defienden que si Benn simpatizó en algún momento temprano con los idearios nazis fue por puro temor (tanto al marxismo como al nacionalsocialismo emergente) o por simple oportunismo. A este respecto nos parece relevante citar a Frank Joseph (2012), que afirma lo siguiente:

Benn himself, it is true, received nothing from the Nazis in exchange for his support except harassment both as a writer and as a practicing physician. He never belonged to the Nazi Party, and in 1935, to escape further difficulty, he joined the German Army and placed himself under the protection of powerful friends on the General Staff. It was at this time that he coined his famous phrase, which, as he reports, made the rounds of the High Command until 1945: "The Army is the aristocratic form of emigration" (p. 119) ${ }^{14}$.

Basta con leer este "Negerbraut" para darnos cuenta de que por mucho que Benn intuyera (como pudo hacerlo Ezra Pound con el fascismo de Mussolini) de manera torpe y equivocada una cierta gloria cultural en el seno del delirante futuro glorioso prometido por Hitler; el poeta estaba radicalmente alejado de la glorificación de la raza aria que serviría como rosa de los vientos del horror nacionalsocialista. Pero dejemos el triste pasado nazi para volver al objeto de estudio de nuestro artículo, la poesía de Benn.

Si los textos anteriores mostraban un ser humano de existencia efímera que tras expirar el último suspiro no dejaba tras de sí honras, honor o dignidad alguna, sino que se convertía en objeto de desecho al mismo tiempo que parodiaban la posibilidad de la resurrección de la carne, en esta ocasión el poeta irá un paso más allá al cuestionar la validez de los valores morales y sociales imperantes. En "Negerbraut" se nos presenta un joven de rubios cabellos con "Brüste noch unentstellt durch Laster und Geburt" ("los pechos aún sin deformar por los pecados y los partos"). En otras palabras, la joven rubia ha fallecido preservando una pureza 
y virginidad que resultaban pertinentes, incluso fundamentales, para la religión y sociedad de su tiempo. Sin embargo, una vez muerta la joven yace indefensa y desnuda en una camilla mientras "Die Sonne wütete in ihrem Haar und leckte ihr die hellen Schenkel lang” ("el sol rabiaba en sus cabellos y lamía los pálidos muslos"). De este modo, un cuerpo que se había reservado con decoro es mostrado de la forma más impúdica y unos muslos nunca acariciados por mano alguna son recorridos por un sol que ya no habrá de darles calor. Para completar la indignidad a la que se ve sometida la joven difunta, alguien ha colocado con descuido otro cadáver junto al suyo. Se trata del negro que da título al poema y del que "zwei Zehen seines schmutzigen linken Fußes ins Innere ihres kleinen weißen Ohrs" ("dos dedos de su sucio pie izquierdo se hincaban en la pequeña oreja blanca"). De este modo, tras preservar virtuosa su himen en vida, una vez muerta su oreja acaba siendo penetrada por dos dedos del pie de un pobre desconocido. Y aún así la joven "sie aber lag und schlief wie eine Braut:/ am Saume ihres Glücks der ersten Liebe" (yacía y dormía como una novia: orlando la felicidad del primer amor"). Si fuertes ecos del topos medieval de la muerte democrática resonaban en "Kreislauf", aquí no podemos dejar de recordar el ancestral consejo del "carpe diem". Críticos como Friederike Eigler y Susanne Kord (1997) aseveran que, "Benn used blackness as a metaphor for savagery and rape” (p. 52)

${ }^{15}$. Sin embargo, consideramos que en este caso el elemento racial no resulta simbólico en ese sentido, sino que simplemente se limita a servir de extremo contrapunto, tanto desde un prisma social como estético. Empleando la terminología postmoderna y de la deconstrucción, los dos cadáveres que se nos presentan no solo juntos sino enlazados mediante el contacto físico no hacen sino deconstruir los opuestos binarios rico/ pobre; negro/caucásico; blanco/negro.

El poema siguiente, "Requiem", continúa la senda iniciada en la composición anterior al llevarnos a visitar una sección de la sala de autopsias en la que encontramos "Auf jedem Tisch zwei. Männer und Weiber/ kreuzweis. Nah, nackt, und dennoch ohne Qual” ("Dos en cada mesa. Hombres y mujeres en cruz. Cerca, desnudos, y pese a ello, sin dolor"). En estas mesas yacen con los cuerpos abiertos y las expertas manos de los cirujanos van retirando órganos, que depositan en cubos conjuntos sin importar realmente a quién perteneció tal o cual víscera. En uno de los momentos de más puro y terrorífico nihilismo de Morgue, Benn identifica este proceso con el de engendrar; lo que una vez más deconstruye uno de los más primarios y elementales opuestos binarios, el de nacer/morir. Se puede observar, pues, que los cadáveres no dan ya a luz nueva vida destinada a disfrutar de una identidad propia e individual, sino nauseabundos restos anónimos. Ante este panorama, no sorprende que la siguiente estrofa niegue por completo la valía de los valores morales y socioculturales de la sociedad europea del momento:

Jeder drei Näpfe voll: von Hirn bis Hoden.
Und Gottes Tempel und des Teufels Stall
nun Brust an Brust auf eines Kübels Boden
begrinsen Golgatha und Sündenfall (Benn, 1991, p.14)

Llegados a este punto postrero que a todos nos aguarda, para Benn no existe cielo ni infierno, castigo ni premio. Por lo tanto, cimentar la breve existencia previa en dichos conceptos (opuesto binarios) resulta ilusorio a la par que inútil. $Y$ es en este momento cuando a pesar del nihilismo imperante en Morgue vuelve a resonar, aunque de manera tímida, el ancestral tema del "carpe diem": "Ich sah, von zweien, die dereinst sich hurten, /laghes da, wie aus einem Mutterleib" ("Yo vi lo que engendraron dos que antaño se jodían, yacer allí, como si hubieran salido de un cuerpo materno").

"Sal der Kreissenden Frauen", siguiente composición de Morgue, enfrenta de manera incluso más dura con el nihilismo absoluto que puebla las páginas de este primer poemario de Benn, ya que en esta ocasión el poetacirujano continúa ejerciendo su papel de frío Cicerón y se traslada desde la sala de autopsias al "Kreissenden Frauen" que da título a la composición. Tampoco ahora será Benn dado a sumarse a los constructos culturales burgueses ni a la moralidad judeocristiana imperante, por lo que lejos de hacer contemplar un escenario de felicidad femenina en el que jóvenes mujeres aguardan ilusionadas el milagro de la vida (a la que vez que 
cumplen con unos dictados religiosos y sociales que, una vez más, vuelven a ir de la mano), enfrenta al lector con el horror más absoluto, al mismo tiempo que niega el consuelo de la dignidad a la que tampoco son merecedoras las protagonistas del texto. Se considera también, en este caso, que no cabe una lectura en clave marxista o postmarxista, puesto que la actitud de Benn, con gran convicción, deriva de un nihilismo influido tanto por los poetas malditos franceses como por la filosofía de Schopenhauer.

En esta composición, Gottfried Benn continúa apostando por la deconstrucción sistemática, absoluta y quirúrgica del decoro poético y los cánones líricos tradicionales, al ceder el protagonismo del poema no a idealizadas féminas o nobles señoras sino a "Die ärmsten Frauen von Berlin — dreizehn Kinder in anderthalb Zimmern, Huren, Gefangene, Ausgestoßene” ("Las mujeres más pobres de Berlín- trece niñas en cuarto y medio, putas, prisioneras, execradas"). Como se aprecia, cincuenta años antes de que Michel Foucault (1965) o Antonin Artaud (1965) dignificaran a los enfermos, "locos" y demás excluidos sociales haciéndolos merecedores de un estudio filosófico al más alto nivel (1965), Benn adelantaba ya esta predilección postmoderna por estos marginados sociales que serán protagonistas casi hegemónicos del postmodernismo literario, filosófico y cultural (desde Adorno hasta John Kennedy Toole o Chuck Palahniuk, los ejemplos de este hecho abundan). Para las parturientas de esta horrenda sala, como para los cadáveres que visitamos con anterioridad, el juramento hipocrático resulta desconocido por completo y las madres han de sumar al dolor físico del parto al mismo tiempo que el sufrimiento moral que les produce la abarrotada sala común, en la que no hay atisbo de intimidad, junto con los crudos comentarios y críticas de las matronas hasta que finalmente, "Schließlich kommt es: bläulich und klein. Urin und Stuhlgang salben es ein" ("Por fin llega: azulado y pequeño. Orina y heces lo ungen"). Inmisericordioso en extremo, como para el autor lo son la naturaleza y sociedad, Benn hace al pequeño abrir los ojos al mundo en un bautismo de "Urin und Stuhlgang" ("orina y heces"), que presagia desde su primera y angustiosa toma de aire el destino inexorable que le aguarda. En cualquier caso, en Morgue nuestro autor es poco dado a sutilezas e insinuaciones, por lo que la estrofa final del poema explicita este hecho de manera gráfica y lapidaria:

\section{Durch dieses kleine fleischerne Stück wird alles gehen: Jammer und Glück Und stirbt es dereinst in Röcheln und Qual iegen zwölf andere in diesem Saal (Benn, 1991, p. 16) ${ }^{17}$.}

Gottfried Benn es consciente de que un catálogo de tragedias ascendente y acumulativo que va intensificando la intensidad gráfica de las descripciones escatológicas puede llegar a producir en un momento dado una cierta insensibilización de la audiencia. Por ello, Morgue es un poemario breve, acerado y contundente en extremo que no llega a la decena de poemas. Pero, aún así, antes de encarar la recta final de la obra, Benn parece querer escapar por un instante del nihilismo atroz que invade todos y cada uno de los recovecos del hospital por el que conduce a su audiencia. De este modo, a la manera de una medida ópera wagneriana, antes de encarar la grandilocuente y sonora coda final, en el poema "Blinddarm" abunda una vez más la sangre, el sufrimiento humano extremo y la gélida mirada de un profesional de la cirugía que observa los cuerpos abiertos de sus pacientes con el desapego propio de un geógrafo que traza con su mirada un mapa mil veces visto antes. Así pues, el poeta alemán narra de manera precisa, dura y fría una complicada operación de apendicitis en la que la anestesia escasea, pero la sangre y el pus abundan en extremo. Sin embargo, al igual que ocurría con el neonato del poema anterior, el protagonista de esta composición esquiva, por el momento, la muerte. De este modo, la intervención que da título a "Blinddarm" concluye como sigue:

Bauch zu. Haut zu. "Heftplaster her!

Guten Morgen, die Herrn."

Der Saal wird leer (Benn, 1991, p. 18) ${ }^{18}$. 
Sin embargo, la victoria de la existencia humana sobre la muerte no habrá de ser sino efímera, ya que las dos últimas líneas del poema adelantan ya que el siguiente texto no concederá alivios al suplicio existencial sino en forma de agonizantes puntos finales, puesto que "Wütend klappert und knirscht mit den Backen/ der Tod und schleicht in die Krebsbaracken" ("Furiosa castañea y rechina con las mejillas la muerte se escurre a la barraca de los cancerosos").

Como anunciaba el poema anterior, tras contemplar la cruenta operación, el siguiente recodo del mórbido recorrido nos conduce al terrible pabellón de cancerosos, en "Mann und Frau Gehn Durch Die Kreebsbaracke". Hasta este punto, Benn no había reparado a la hora de mostrar los efectos que la edad, la enfermedad o el mero azar causan en el cuerpo humano, bien exponiendo cadáveres que una fueron jóvenes hermosos y sanos o bien invitando al lector a asistir a una cruda operación quirúrgica. También los lectores ya sido testigos del cruel nacimiento de un bebé cuya mera mortandad y ascendencia social le hacían heredero de una senda de sufrimiento y pesar. Mórbidos como estos temas puedan resultar, y por terrorífico que el cese de la existencia resulte, de los cuerpos yermos de poemas anteriores emanaba cierta placidez (aún desprovistos tanto de hálito vital como de dignidad), puesto que, desde el prisma nihilista y ateo de Benn, con el fin de la existencia corpórea concluye nuestro recorrido y, de ese modo, la muerte no deja de ser un punto y final a un tránsito que en la mayor parte de etapas se ve caracterizado por el dolor y la decadencia extremas. En resumidas cuentas, para el racionalista extremo de Gottfried Benn la vida no era menor valle de lágrimas de lo que resultaba para el misticismo católico. Huelga decir que para Benn no espera tras el árido valle un Dios benefactor, sino que es una nada absoluta la que libera del dolor, pesar y preocupaciones. Sin embargo, en "Mann und Frau Gehn Durch Die Kreebsbaracke" la muerte no resulta misericordiosa, puesto que lejos de asestar un certero golpe de guadaña instantánea en forma de atropello por carro, se deleita en torturar de manera lenta e inexorable a unos pobladores del pabellón de enfermos de cáncer a los que "Man läßt sie schlafen. Tag und Nacht" ("dejan dormir. Día y noche"), ya que "Den Neuen/ sagt man: hier schläft man sich gesund" (“A los nuevos se les dice: aquí el sueño es curativo”). O, en otras palabras, tanto facultativos como los propios pacientes saben que llegado este punto terrible el "memento mori" ha de dar paso al "imitatio mori” si se aspira a encontrar si quiera un instante de descanso.

Duermen, pues, unos pacientes que se ven obligados a tolerar pesares y quebrantos tan indescriptibles e inconceptualizables para aquellos que no comparten su aciago destino que los deshumaniza: "Hier diese blutet wie aus dreißig Leibern./ Kein Mensch hat so viel Blut" ("Esta mujer sangra como si tuviera treinta cuerpos. Ningún ser humano tiene tanta sangre"). Los enfermos terminales pasan sus últimos días en el mundo alejados de la sociedad, en unas condiciones higiénicas deplorables, retorciéndose de dolor y ya sin esperanza ni sueños, ya sean carnales, espirituales, individuales o sociales:

Komm, hebe rubig diese Decke auf.
Sieh, dieser Klumpen Fett und faule Stäfte,
das war einst irgendeinem Mann groß
und hieß auch Rausch und Heimat (Benn, 1991, p. 22) ${ }^{19}$.

Nos encontramos, en definitiva, ante la más temible de las salas del sombrío hospital por el que nos ha hecho transitar Gottfried Benn. Tras esta última puerta, nos espera un último poema que cierra Morgue de manera lapidaria: "Nachtcafé". Cabría suponer que escapar de los horrores del hospital y mudar camillas hospitalarias por mesas de café y gemidos de enfermos terminales por música popular supondría un, si quiera, mínimo consuelo para poeta y lector. Sin embargo, en este café nocturno al que se dirige el Benn doctor tras una dura jornada de trabajo hospitalario la melodía es escatológica, "Das Cello trinkt rasch mal. Die Flöte/ rülpst tief drei Takte lang: das schöne Abendbrot" ("El violoncelo se toma un trago. La flauta eructa profundo en tres compases: la hermosa cena"); los parroquianos no exhiben mayor sensualidad en la piel de la de los enfermos, 


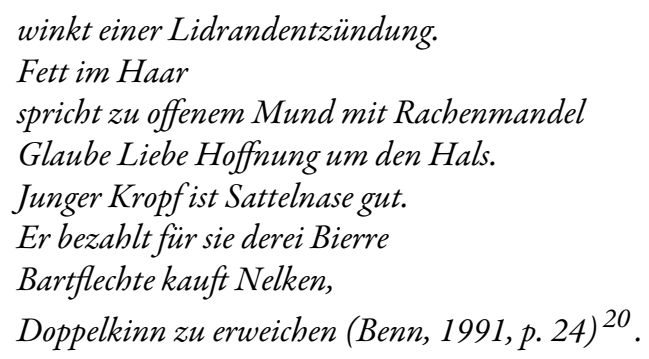

En un interesante artículo publicado en el año 2007, Andreas Anglet analiza el rol que los cafés desempeñan en la poesía de Apollinaire y Benn, este crítico subraya la importancia que estos espacios públicos tienen para el controvertido autor alemán en los siguientes términos: "The night cafe is the modern manifestation of the primeval horde's cave. Like in Freud's psychoanalytical archeology in Benn's poems under the day's surface of the urban social life, there reigns an anarchic realm of sexual appetites and bodily decay" (p. 219) ${ }^{21}$.

\section{Conclusiones: Lo QUE LA AUTOPSiA ARroJa}

Cabría en este punto plantearse si el Benn cirujano, que tan bien conoce las sendas sanguinolentas que recorren el interior del más hermoso de los cuerpos humanos sea ya incapaz de ver el mundo exterior sin intuir el interior; si tras despedazar cadáveres, atender a nacimientos que se asemejan a rituales de muerte y hacer una última ronda por el pabellón de cancerosos no sea ya capaz de hallar alivio en los pequeños, imperfectos, placeres mundanos a los que sus conciudadanos se entregan, desconocedores del mal que ya comienza a corroer su interior y del funesto destino que les aguarda. Resultaría en extremo sencillo tildar a Benn de ser un verdadero adalid del nihilismo, que niega la promesa de una vida espiritual futura al mismo tiempo que el carpe diem para regodearse en los elementos más mórbidos y siniestros del ser humano, de manera enfermiza. En este sentido, Charles Glicksberg (1963) apunta que:

Defiantly secular, literary nihilism affirms only the necessity for revolt against the human condition. It beholds in the spectacle of suffering a supreme example, one of many, of the meaninglessness of existence. Upholder of the Nietzschean faith in the aesthetic resolution of the mystery of being, Gottfried Benn, the nihilist par excellence, turns to art as his last defence. Nihilism, he concludes, is inevitable in the twentieth century. He could not transcend his nihilism. Literature for him was but one of the drugs that made life bearable (p. 16) ${ }^{22}$.

Otros expertos, como Jacqueline Rollfinke (1996) consideran que el nihilismo y la escatología presentes en el corpus poético de Benn en realidad esconden hondas preocupaciones filosóficas, que van mucho más allá de la mera negación y fascinación con lo mórbido: "Benn's excremental metaphors reflect the same loathing of the human body that can be found in Martin Luther's Table Talk. Luther, however, looked forward to the salvation of the soul; Benn could not share this optimism" (p. 160) ${ }^{23}$. Hans Kohn (1960) también se expresaba en esta línea (cuando Benn era aún un poeta incómodo al que no se perdonaba su breve relación con el funesto Nacionalsocialismo de Hitler):

Gottfried Benn had no doubt that the Quarternary period of geological development was coming to an end, that Homo sapiens was becoming obsolete. No expression was extreme enough to voice the hatred of western civilization, of liberalism, of humanitarianism. The philosophy of Martin Heidegger, the political theory of Carl Schmitt, the theology of Karl Barth-all these convinced the German intellectuals that mankind had reached a decisive turning point, an unprecedented crisis, into which liberalism had led man. These intellectuals looked down upon the West with the same contempt later displayed by the leaders of National Socialism (p. 327) ${ }^{24}$.

Otras voces críticas interpretaron la poesía de Benn de manera más frívola desde la misma publicación de Morgue. En este sentido, es especialmente importante recordar que cuando el poemario vio la luz por primera 
vez Zwiebelfisch (revista que había sido bastión de la poesía avant-garde) no dudó en afirmar al respecto: "A person who goes mad used to see white mice dancing. Modern Berlin has gone him one better; it sees rats" (Pachter, 1982, p. 94) ${ }^{25}$. Se considera que la reseña de Zwiebelfisch resulta, en efecto, perfecta; pero no porque la poesía de Benn resultara oportunista, puesto que es bien sabido que la provocación y radicalidad extrema en un autor novel suelen ser mejores garantías de reconocimiento e incluso éxito comercial que un verso bien medido y una temática elegante. Ni porque los lectores berlineses sucumbieran a los placeres de la provocación pura que Zwiebelfisch achacaba a Benn, sino porque este poeta, en su cruel y brutal poemario se convierte en profeta postmoderno que, gracias al don de la ciencia, predice los funestos acontecimientos que están por venir.

Por su parte, la escatología y desesperación profunda que emana de Morgue no son en verdad sino reflejo del angst que permeaba Alemania en el año 1912 y que muy pronto acabaría por dar como maléficos frutos la atroz Primera Guerra Mundial y, después, las atrocidades del Tercer Reich.

Como conclusión, queda sino afirmar que Morgue resulta sublime en cuanto atroz y hermoso, al mismo tiempo que sirve de terrible reflejo social de una Alemania sumida en el caos y la incertidumbre que se niega a ver (parafraseando el título de la obra cinematográfica de Ingmar Bergman) crecer el traslúcido huevo de una serpiente que habría de eclosionar en breve para asolar no solo Alemania sino Europa y partes importantes de Asia y África. Al mismo tiempo que destruirá la fe humana en el progreso científico como aliado moral y en las grandes certezas filosóficas del pasado. Puesto que, desde nuestro modesto prisma, tanto Gottfried Benn como las dos grandes Guerras Mundiales y sus consecuencias no dejan de ser mórbidas y fundamentales semillas del postmodernismo posterior. Para finalizar, un parafraseo del genial poeta francés Charles Baudelaire (con el que tanto comparten Benn y el postmodernismo) afirmando que Benn es una más de las desiguales y descreídas semillas que germinarán en las flores heterogéneas y terribles, en cuanto sublimes, del postmodernismo.

\section{ReFERENCIAS}

Addison, J. (1712). The Works of the Right Honourable Joseph Addison. Londres, Reino Unido: Cadell.

Altman, A. (1973). Moses Mendelssohn: A Biographical Study. Liverpool, Inglaterra: Littman Library of Jewish Civilization.

Anglet, A. (2007). The Café in Benn's and Apollinaire's Lyrical Focalisations of the City. Kultur Poetik, 7(2), $215-233$. Artaud, A. (1965). Antonin Artaud anthology (2 ed.). San Francisco, Estados Unidos: City Light Books.

Baudelaire, C. (1971). Les fleurs du mal. Paris, Francia: Livre de poche.

Baudelaire, C. (2009). Las flores del mal, traducción, introducción y notas de Pedro Provencio. Madrid, España: EDAF. Benn, G. (1991). Morgue y otros poemas; traducido por Verónica Jaffé. Caracas, Venezuela: Pequeña Venecia.

Blackmore, A. M. (1999). Six Nineteenth Century French Poets with Parallel French Translation. Nueva York, Estados Unidos: Oxford University Press.

Blackwell, M. (2003). The sublimity of taste in Edmund Burke's A Philosophical Enquiry into the Origin of Our Ideas of the Sublime and Beautiful. Philological Quarterly, 82(3), 325-347.

Culpeper, J. (1997). History of English. Nueva York, Estados Unidos: Routledge.

Desoir, M. (1906). Ästhetik und allgemeine Kunstwissenschaft. Stuttgart, Alemania: F. Enke.

Eck, C. (2012). Translations of the sublime: the early modern reception and dissemination of Longinus' Peri hupsous in rhetoric, the visual arts, architecture and the theatre. Boston, Estados Unidos: Brill.

Egon Morgan, I. (2009). The Potentiation of Meaning through Translative Reading. (Tesis doctoral). Stanford University.

Ford, A. (1993). Klaus Mann and the Weimar Republic: literary tradition and experimentation in his prose, 1924-1933. (Tesis doctoral). University of Nottingham. Nottingham. 
Foucault, M. (1965). Madness and civilization; a history of insanity in the age of reason. Nueva York, Estados Unidos: Pantheon Books.

Frank, J. (2012). Responses to modernity: Essays in the politics of culture. Nueva York, Estados Unidos: Fordham University Press.

Glicksberg, C. (1963). The tragic visión in tweentieth-century literature. Carbondale, Estados Unidos: Southern Illionois University Press.

González, H. (2014). La danza macabra. Revista Digital de Iconografía Medieval 6(11), 23-51.

Hammermeister, K. (2002). The German Aesthetic Tradition. Cambridge, Inglaterra: Cambridge University Press.

Higuchi, K. (1994). Genealogy of the aesthetics of the sublime- Addison and Shaftesbury. The Scriblerian and the KitCats, 27(1), 2-3.

Hillebrand, B. (1987). Über Gottfried Benn. Kritische Stimmen 1912-1956. Frankfurt, Alemania: Main Fischer Verlag. James, D. (2012). Art, Myth, and Society in Hegel's Aesthetics. Nueva York, Estados Unidos: Continuum.

Kant, I. (2016). The Critique ofJudgement: Critique of Aesthetic Judgement. Scotts Valley, Estados Unidos: CreateSpace Independent Publishing Platform.

Kant, I. (1876). Crítica del jucio, traducido por Alejo García Moreno. Madrid, España: Librerías de Francisco Iravedra. Kittler, F. A. (1990). Discourse networks 1800/1900. Stanford, Estados Unidos: Stanford University Press.

Kohn, H. (1960). The mind of Germany: The education of a nation. Nueva York, Estados Unidos: Charles Scribner's Sons.

Kord, S. y Eigler, F. (1997). The feminist enciclopedia of German literature. Westport, Estados Unidos: Greenwood Press.

Mann, K. (2013). Open Letter to Gottfried Benn (1913). En A. Rabinbach. The Third Reich Sourcebook (pp. 460-461). Berkeley, Estados Unidos: University of California Press.

Martín Párraga, J. (2015). Joseph Addison y The Spectator. Estudio critico y selección de textos. Granada, España: Comares.

McIsaac, P. (2019). "Es schmeckt nach Kino": Provocative Display and Gestures of Exposure in and around Gottfried Benn's Morgue und andere Gedichte. German Studies Review, 42(2), 213-238.

Murphy, R. (1999). Theorizing the Avant-Garde: Modernism, Expressionism, and the problem of Postmodernity. Cambridge, Inglaterra: Cambridge University Press.

Pachter, H. (1982). Weimar studies. Nueva York, Estados Unidos: Columbia University Press.

Powell, L. (2008). Nature in Rilke, Benn, Brecht, and Doblin. Woodbridge. Woodbridge, Inglaterra: Boydell \& Brewer.

Rollfinke, J. (1996). The call of human nature: The role of scatology in modern German literature. Amherst, Estados Unidos: University of Massachussetts Press.

Solène, T. (2014). Ce que maudit veut dire: le cas Verlaine. Revue Verlaine, 12, 277-294.

Žižek, S. (1994). Mapping ideology. Nueva York, Estados Unidos: Verso.

\section{Notas}

1. La ecuación que ofrece Baudelaire de ‘iviva la revolución!' con ¡viva la muerte!' tiene un claro eco en su deseo de ser al mismo tiempo víctima y verdugo (traducción propia).

2. Hipócrita lector, -mi semejante- ¡mi hermano! (traducción de Pedro Provencio, en Baudelaire, 2009, p. 48).

3. Igual que un libertino pobre que besa y come

el pecho maltratado de una antigua buscona,

robamos al pasar un placer clandestino

que exprimimos a fondo como una naranja añeja.

Apretado, hormigueante, como un millón de larvas,

retoza en nuestros sesos un pueblo de Demonios,

y cuando respiramos, baja la Muerte a nuestros pulmones

en un río invisible, con sordos lamentos (traducción de Pedro Provencio, en Baudelaire, 2009, p. 47). 
4. Ofrecemos a continuación la traducción al inglés que del poema realizara Martin Sorrell en 1999. Se opta por ofrecer esta versión al no haber sido capaces de localizar una traducción al castellano que capte el espíritu del texto fuente con tanta fidelidad, al mismo tiempo que de manera tan poética:

I never knew you, never loved you.

I don't know you still and love you even less.

Your disreputable name would not sit well

on my shoulders. If I've some rights to be

Your witness, it's because you were prostrate in prayer

before the Feet held first by cold nails

Then by the fainting rush of sinful women-

Those Feet so much anointed with holy oil,

So kissed by parched mouths- prostrate, like me, like all

Thirsting famished souls made beautiful by hope

As they grope their way towards dreadful Cross,

The one true Calvary, the Calvary where

Darting doubt, art, grimaces lose their way

And weep. A simple death, then, for simple men? (Blackmore, 1999, p. 251).

La traducción al castellano que sigue es propia:

Nunca te conocí, tampoco te amé.

Aún no te conozco y te amo incluso menos.

La mala fama que acompaña a tu nombre no me

resulta oportuna. Si tengo algún derecho es el de ser

tu testigo es porque te arrodillaste primero

ante los pies sujetos por fríos clavos.

Más tarde ante el impulso extasiado de mujeres pecaminosas-

Esos pies tan ungidos por aceite sagrado,

tan besados por bocas resecas- arrodillado como yo, como todos.

Sedientas almas hambrientas embellecidas por la esperanza

mientras avanzan a tientas hacia la temible Cruz,

el verdadero y único Calvario, el Calvario donde

arrojando dudas el arte hace muecas y pierde su camino

sollozando. ¿Una muerte simple, entonces, para hombres simples?

5. Benn no es en absoluto un autor nuevo o aún por descubrir, ya que había publicado su primer libro -un volumen brutal de poemas expresionistas llamado Morgue- en 1912 y en el momento actual se le considera como el más grande poeta alemán después de Rilke (traducción propia).

6. La flor azul de la naturaleza romántica aquí se hace yacer de manera ritual, junto con el sujeto de la autonomía humanista que se revela como anatomía diseccionada, todo ello recubierto por los tonos irónicos de una ceremoniosidad litúrgica implícita (traducción propia).

7. La curiosa fascinación que provocaba la contemplación de los cadáveres expuestos en sus contemporáneos llevo a los escritores y críticos alemanes a desarrollar la morgue como un topos de exposición y visualidad (traducción propia).

8. La satisfacción referente a lo sublime de la naturaleza es, pues, simplemente negativa (mientras que la que se refiere a lo bello es positiva); es el sentimiento de la imaginación, privándose ella misma de su libertad y obrando conforme a una ley distinta de la de su ejercicio empírico. Por esto recibe una extensión y un poder mayor que los que sacrifica; mas el principio esta\# para ella oculto, mientras que siente el sacrificio o la privación, y al mismo tiempo la causa a la cual se halla sometida (traducción de Alejo García Moreno, en Kant, 1876, p. 161).

9. Benn vivió la mayor parte de su vida en unos momentos muy agitados desde el punto de vista político y los acontecimientos en ese frente contribuyeron a dar forma a su visión del mundo; de manera más concreta e importante, sus convicciones y prácticas artísticas proceden de una tradición que estaba conformada casi exclusivamente por la política. Pero, al mismo tiempo, la producción lírica de Benn, de manera francamente sorprendente, resulta casi por completo apolítica; ya que, aunque nunca fuera una persona apolítica, su poesía, su verdadero arte, nunca se convirtieron en políticos (traducción propia).

10. [Mann] proponía, en su debate con Gottfried Benn, que si el autor no conseguía dirigirse al momento histórico concreto al desafiar su contexto social y político, estaría propiciando su propia caída, ya que su trabajo acabaría siendo juzgado como irrelevante (traducción propia).

11. Döblin, Benn and Kafka] son "avant-garde" no solo en el sentido en que su cuestionamiento de la forma en que estas convenciones apoyan la idea de "normalidad” del mundo burgués, sino también en la forma en que desarrollan una serie 
de "discursos oposicionales" que aspiran a revisar las prácticas artísticas institucionalizadas mediante las cuales ciertos valores resultan privilegiados (traducción propia).

12. La transmisión verbal [es entendida] como neurosis, sin base alguna transcendental o en el ego creativo del poeta; una selección del medio sin ninguna referencia a la realidad, a los antecedentes incomprensibles de los medios de comunicación. El mundo que hasta el momento siempre había sido presentado al mundo opera en un cierto umbral de reacción psíquica, que era conocido como el discurso de la naturaleza y la naturaleza del discurso. La psicofísica [de Ro\#nne] hace que ambos desaparezcan (traducción propia).

13. Sin embargo, el Sr. Benn no solo hurga con su pluma en heridas apestosas, sino que también lo hace en el erotismo, y el modo en que lo hace, le permite convertirse en el sucesor de aquel que fue expulsado de la casa [Alemania] debido a su obscenidad antinatural (traducción propia).

14. Es cierto que el propio Benn nunca recibió nada de los Nazis a cambio de su apoyo, Muy al contrario, fue acosado por estos, tanto como escritor como en su faceta de médico. Nunca perteneció al partido Nazi y en 1935, para librarse de futuras dificultades, se unió al Ejército Alemán, ubicándose de este modo bajo la protección de algunos amigos poderosos con que contaban dentro del Estado Mayor. Fue durante este periodo en que acuño una célebre frase que, como él mismo explica, se hizo popular entre los miembros del Alto Mando hasta 1945: "El Ejército supone una forma aristocrática de emigración" (traducción propia).

15. Benn uso el color negro como metáfora del salvajismo y la violación (traducción propia).

16. Cada uno llena tres cazuelas: desde el cerebro hasta los testículos.

Y el templo de Dios y el Corral del demonio

ahora pecho a pecho en el fondo de un cubo

se ríen del Gólgota y del pecado original (Benn, 1991, p. 15, traducción de Verónica Jaffé).

17. Por este pequeño pedazo de carne

pasará todo: desolación y felicidad.

Y cuando muera entre estertores y sufrimientos, otros doce dormirán en este pabellón (Benn, 1991, p. 17, traducción de Verónica Jaffé).

18. Vientre cerrado, piel cosida. ¡Esparadrapos acá!

Buenos días señores.

La sala se vacía (Benn, 1991, p. 19, traducción de Verónica Jaffé).

19. Ven, levanta sin miedo esta manta.

Mira, este grumo de grasa y humores podridos,

Alguna vez fue importante para un hombre y también se llamaba patria y delirio (Benn, 1991, p. 23, traducción de Verónica Jaffé).

20. Dientes verdes, espinillas en la cara

le hace señas a una inflamación de párpado.

Grasa en el cabello

Le habla a boca abierta con almendra faríngea

$\mathrm{Fe}$, amor y esperanza alrededor del cuello.

Joven bocio quiere a nariz de dos bultos

La convida a tres cervezas.

Sicosis compra claveles.

Para ablandar a papada (Benn, 1991, p. 25, traducción de Verónica Jaffé).

21. El café nocturno es la manifestación moderna de la cueva primitiva de la horda. Como en la arqueología psicoanalítica de Freud, en los poemas de Benn bajo la superficie de la vida social urbana del día, en estos se impone un reino anárquico de apetitos sexuales y decadencia corporal (traducción propia).

22. Desafiantemente secular, el nihilismo literario tan solo afirma la necesidad de rebelarse contra la condición humana. Contempla en el espectáculo del sufrimiento un supremo ejemplo, uno de los muchos, del sinsentido de la existencia. Firme defensor de la fe nietzscheana, en la resolución estética del misterio del ser, Gottfried Benn, el nihilista por excelencia, recurre al arte como última defensa. Concluye que el nihilismo es inevitable en el siglo veinte. En su concepción de que el arte moderno testifica la desaparición de todo significado, está de hecho cerca de la visión trágica. Nunca pudo trascender su nihilismo y para él la literatura era una de las drogas que hacían la vida soportable (traducción propia).

23. Las metáforas excrementales de Benn reflejan el mismo desprecio por el cuerpo humano que encontramos en las Charlas de sobremesa, de Martín Lutero. Lutero, aspiraba a la salvación del alma. Sin embargo, Benn no podía compartir su optimismo (traducción propia).

24 Gottfried Benn estaba convencido de que el periodo cuaternario de desarrollo geológico estaba llegando a su fin, de que el Homo Sapiens se estaba quedando obsoleto. Para él no había expresión lo suficientemente extrema como para expresar el desprecio que sentía hacia la civilización occidental, el liberalismo o el humanitarismo. La filosofía de Martin 
Dr. Javier Martín Párraga. Gottfried Benn y la sublime belleza de la crueldad

Heidegger, la teoría política de Carl Schmitt y la teología de Karl Barth convencieron a los intelectuales alemanes de que la humanidad había llegado a un punto decisivo, a una crisis sin precedentes a la que el liberalismo había conducido al ser humano. Estos intelectuales miraban a Occidente con el mismo desprecio que más tarde exhibirían los líderes del Nacionalsocialismo (traducción propia).

25. Una persona que se vuelve loca solía ver ratones blancos danzando. El Berlín moderno lo ha mejorado, ya que ve ratas (traducción propia).

Todos los derechos reservados. Universidad de Costa Rica. Esta revista se encuentra licenciada con Creative Commons. Reconocimiento-NoComercial-SinObraDerivada 3.0 Costa Rica. Correo electrónico: humanidades@ucr.ac.cr/Sitioweb: http: //revistas.ucr.ac.cr/index.php/humanidades CC BY-NC-ND 